\title{
LA ESCENA DEL SIGLO XIX, «DOMICILIO DE TODAS LAS ARTES»
}

\author{
Alberto ROMERO FERRER \\ Universidad de Cádiz
}

Decía Ortega en su Idea sobre teatro que cuando se piensa en el término «teatro» podemos estar refiriéndonos a una serie de conceptos, aunque relacionados entre sí dentro del mismo campo semántico, bien distintos. Puede tratarse del género dramático, del texto literario, de la actitud engañosa de la apariencia y también del lugar de la representación'. De todas ellas es, tal vez, esta última la que podría englobar a todas las demás, por la especial significación del espacio como lugar donde se pone en escena el texto dramático y donde se produce su esperado encuentro con los espectadores. Así, cuando decimos «vamos al teatro» marcamos significativamente nuestra intención de asistir a una representación teatral en un lugar determinado, pensado y proyectado para tal actividad. $Y$ este lugar, a lo largo de la historia, gracias a su vocación estrictamente social también ha venido evolucionando y metamorfoseándose conforme aquellas transforma-

1 «Edificio o sitio destinado a la representación de obras dramáticas o a otros espectáculos públicos propios de la escena. 2. Sitio o lugar en que se realiza una acción ante espectadores o participantes. 3. Escenario o escena. 4. Lugar en que ocurren acontecimientos notables y dignos de atención. Italia fue el teatro de aquella guerra. 5. Conjunto de todas las producciones dramáticas de un pueblo, de una época o de un autor. El teatro griego. El teatro del siglo XVII. El teatro de Calderón. 6. Literatura dramática. Lope de Rueda fue uno de los fundadores del teatro en España. 7. Arte de componer obras dramáticas, o de representarlas. Ese escritor y ese actor conocen mucho teatro. 8 . Acción fingida y exagerada. Arturo le echa mucho teatro a sus intervenciones. 9. Práctica en el arte de representar comedias. Ese actor tiene mucho teatro.» (DRAE). 
ciones sociales se venían produciendo, proyectando en él su particular modo en entender e interpretar el mundo.

Tal vez, uno de esos cambios más radicales podamos situarlo en el revolucionario tránsito del Antiguo Régimen a la Modernidad -de la Ilustración al Romanticismo-, en el camino, precisamente, que va del corral de comedias y al civilizado edificio que, desde finales del XVIII y a lo largo de todo el XIX, se impone para la representación teatral: el teatro a la italiana, y que desde Jovellanos, Diderot o D'Alembert se convierte en «el domicilio de todas las artes» (Jovellanos 1963, pág. 498). Un largo recorrido, pues, que marca también una radical transformación en la propia concepción teatral que a partir de ahora verá, por ejemplo, sustituido el ambiente de la fiesta barroca por una moral docente, que pretende hacer del teatro una prolongación, incluso física, del pensamiento burgués dominante. El teatro se convertía, pues, en el gran medio de distracción de la burguesía, además de configurarse como uno de los símbolos más emblemáticos de la cultura del XIX en toda Europa. Así, la imagen teatral del período es la que ha pervivido hasta la actualidad, a pesar de algunos importantes cambios estéticos del XX.

La institucionalización del teatro, la mayor profesionalización del actor, el desarrollo de la pintura escénica o el nuevo concepto del edificio del teatro son algunos de los factores que marcan y determinan la escena del XIX de un modo absolutamente radical frente a la tradición anterior, con la que rompe de manera muy efectiva, a pesar de algunas pervivencias autóctonas que, por otro lado, también se someten a los nuevos esquemas del género dramático. En otras palabras, nos encontrábamos en la «Era del Teatro Burgués» -en palabras de Robert Pignarre (1971 y 1975) y Ricard Salvat (1981)- cuando el arte de la escena se convierte en «lo más inteligente de sus diversiones, de su fiesta cotidiana y de su lujo», y se despliegan todos los mecanismos que transforman, ya definitivamente, la simplicidad del corral de comedias en un complejo y artificioso espacio arquitectónico pensado para el ocio y la sociabilidad de la nueva clase dominante.

Desde esta perspectiva también había que considerar cómo afectaban dichos cambios al texto dramático (Romero Ferrer 1996), sometido ahora a otro tipo de condicionantes y exigencias con las que tendrá que pactar el dramaturgo para ver sus textos representados, de acuerdo con los nuevos cánones estéticos, pero también económicos y sociales que conlleva la nueva escena, basada, de manera muy fundamental, en la técnica de la caja italiana y el desarrollo de todas sus posibilidades estéticas.

Efectivamente, el siglo XIX institucionaliza el teatro a la italiana como la fórmula de concepción escénica que más y mejor se adapta a las necesidades de entretenimiento y de simbolización social de la emergente sociedad burguesa. Llamado así por haber surgido en el seno de las ciudades de Roma, Venecia, 
Florencia o Nápoles, el teatro a la italiana es un teatro del espectador, y más concretamente, de su mirada siempre polivalente, y en este caso, a caballo entre lo público y lo privado. Este teatro del espectador es también el teatro de Europa, pues pertenece a todo el continente y a todo representa, a pesar de la constante e inevitable referencia a sus raíces en el Renacimiento italiano. Como espacio europeo por excelencia, que lo es, frente a otras formas también nacidas en Europa pero más restringidas como son, por ejemplo, el teatro griego o la escena isabelina, nacido en Italia y relanzado desde Francia con cierta rapidez se significa independientemente de las distintas variaciones más particulares según los países. Así, ya a finales del XVIII se impone la paradoja de individualizar, por un lado, cada uno de estos espacios y a la vez de convertirlos cada uno de ellos en patrones y modelos. Y todo ello dentro de un intenso debate teórico a cerca de la definición de la forma interior del auditorio, que debía ajustarse a la necesaria, igualitaria y óptima visión y audición del espectáculo (Graells 1985).

Europa supo, a partir de entonces, crear de acuerdo con un modelo ideal, las múltiples variaciones siempre reconocibles para un posible espectador que recorriera el continente desde Nápoles a París y a Sevilla, y desde lugares tan populosos como San Petersburgo hasta ciudades mucho más pequeñas del sur de Andalucía como Cádiz o Málaga. En todos los casos, la experiencia iba a resultar familiar, en todos esos lugares el espectador iba a encontrar un espacio común: la misma estructura, la misma disposición, los mismos colores -oro y rojo preferentemente (Banú 1989)-, las mismas referencias, incluso los mismos repertorios. El extranjero --como bien experimentaría Stendhal- se sentiría como en su casa estuviese en el Liceo de Barcelona, en el Teatro Argentina de Roma, en la Ópera de París, en el San Carlos de Nápoles o el Teatro Real de Turín (Tamburini1983).

Pero a esta unidad del espacio, también le corresponde una unidad en el tiempo: el siglo XIX, independientemente de los cambios o las rupturas que pueden acarrear la Historia. El espacio teatral permanecerá inalterable y homogéneo, convenciendo de su armonía y funcionalidad a un cuerpo social -la burguesíaconsciente de su fuerza, y proyectándose en él como espejo superlativo de su protagonismo político y económico (Seco Serrano 1973). Así, en el teatro a la italiana, perdurable en el tiempo gracias a su coherencia estética y funcional, la permanencia prevalece sobre la diferencia. Gracias a ello, el teatro a la italiana es el único espacio mental capaz de interrelacionar su función con su proyección. Es, pues, un lugar concreto, abstracto e imaginario a la vez, en el que el espectador consigue hacer un recorrido que jerarquiza su propia presencia en el teatro. $\mathrm{Su}$ protagonismo concierne al preámbulo, al introito, a la introducción al espectáculo, a todo aquello que se representa incluso mucho antes de que comience la función teatral propiamente dicha. 
Pero de la misma manera que el teatro a la italiana construye un espectadoractor, y se convierte en propia función teatral con decorado propio -el «foyer», las escaleras, los palcos, la sala-, también transforma sobremanera lo que acontece más allá del telón y la embocadura de la escena. El nuevo teatro de la mirada condiciona el escenario como el lugar pretexto para el encuentro de las distintas miradas de los espectadores, que, a diferencia ahora del corral de comedias o la escena griega, deben afilar su vista para una escena, pensada y diseñada para ser mirada, como si de un cuadro en movimiento se tratara.

En este sentido, no hay que perder de vista las distintas transformaciones que se producen en el complejo tránsito de la Ilustración al Romanticismo en lo que respecta tanto a la propia concepción de la escena como de la literatura dramática. Así, mientras se sustituye el concepto poético de mimesis aristotélica por el de mimesis costumbrista, y que implica, entre otras transformaciones, que la literatura se llene de realidad y que hable de lo que pasa «entre nosotros» (Escobar 1988 y 1994), también se están produciendo fuertes transformaciones de decoro que, en relación con el problema teórico anterior, afectan a la concepción misma del texto dramático y su visibilidad en la escena.

Así, a partir de las reformas ilustradas del último tercio del siglo XVIII, la escena debía ofrecer modelos de conducta social y ejemplaridad moral. En el caso de la comedia, por ejemplo, estos nuevos objetivos se cumplían con más o menos acierto mediante la ambientación contemporánea de los conflictos y la localización relativamente próxima y doméstica de las intrigas dramáticas. Ya en el siglo XIX, el desarrollo conjunto de estas líneas temáticas e intencionales, con fuertes componentes éticos y estéticos, conlleva implícitamente la transformación de la escena en espacio de la privacidad y escaparate social, con todas las contradicciones y paradojas que conlleva dicha convivencia de objetivos. En esta líneas tenemos, por ejemplo, las palabras de Tomás Rodríguez Rubí (1847), para quien el teatro debía ser un reflejo, un dibujo de costumbres:

Es, pues, el teatro, según mi leal entender, y de estos ejemplos se desprende, escuela, porque advierte, enseña, ilustra; y «refiejo de costumbres», porque las modela, dibuja o retrata: una institución que, aunque de naturaleza compleja, es, en el mejor ejercicio de sus funciones, uniforme, concreta, indivisible (pág. 432).

Y un poco más adelante se pregunta «¿qué ha de hacer el teatro al desempeñar su papel de retratista, si no usar los colores que la sociedad misma le sirve de paleta?» (pág. 432).

Todos estos cambios serán posibles gracias a las facilidades técnicas que ofrecía la caja italiana, concebida precisamente como una férrea estructura -foso, telar y escena- donde dar ilusión de realidad -verosimilitud- a un mundo de ficción literaria, bajo las normas ópticas y arquitectónicas de la perspectiva italiana 
y el punto de fuga. Se conseguía con ello dar sentido bidimensional a una realidad tridimensional, que el espectador, gracias al juego de perspectivas, aceptará como verosimil. Una arraigada y fuerte convención teatral apoyada en el hecho sociológico de la tradición y en el carácter ciertamente retrógrado del lenguaje teatral frente a otros lenguajes artísticos más proclives a cambios y rupturas.

En otras palabras, lo que hacía tres siglos había surgido como el efecto concreto de aplicar al teatro los progresos técnicos de la pintura en el Renacimiento, con la intención de conseguir efecto de realidad, ahora se convierte en el mecanismo más perfecto para, desde supuestas bases morales, retratar jerárquicamente aquella misma sociedad que constituye, a su vez, su objeto de censura moral y su público mismo. La caja italiana resultaba, ahora, ser un aparentemente sencillo espejo del resto de la sala teatral. A la jerarquía implícita en la distribución de los diferentes públicos en las también jerárquicamente diferentes zonas de la sala, correspondía una cierta simetría dentro del palco escénico, gracias a la estructura interna de la caja teatral y sus diferentes planos y embocadura.

Sin embargo, la nueva verosimilitud realista de la escena, además de exigencias de tipo moral y decoro literario, implicaría también un extraordinario desarrollo de la escenografía: una de las aportaciones más interesantes del siglo XIX a la historia del teatro occidental (Arias de Cossío 1991). Así, a la austeridad escenográfica del corral de comedias, sigue una opción que, gracias a las motivaciones de la política ilustrada, por un lado, y a las exigencias del nuevo público, por otro, se convierte en esencial dentro de la concepción escénica del siglo de la burguesía. Lo que en el Barroco era algo accesorio y circunstancial, y las reformas ilustradas como las del Conde de Aranda (Rubio Jiménez 1998) pretenden imponer por supuestos tan teóricos como la verosimilitud y credibilidad de los textos, logrando profundizar así en sus funciones docentes, en el siglo XIX se impone como uno de los elementos más importantes y más básicos del espectáculo, llegando a convertirse incluso en uno de sus reclamos más atractivos.

Desde esta nueva perspectiva, la comedia y el drama romántico, la comedia de espectáculo, el drama histórico, la alta comedia, la zarzuela o la ópera -géneros todos muy del Diecinueve- centran una buena parte de sus respectivas estructuras teatrales en la primacía de los decorados y los demás elementos que componen la escenografía. El desarrollo extraordinario, por ejemplo, de las acotaciones en los mismos textos dramáticos, su minuciosidad descriptiva, la propia poética argumental de las obras que hacía corresponder estados de ánimo de los personajes con los paisajes naturales de la escena, la espectacularidad del drama romántico o de la ópera, o la compleja estructura visual y aparatosidad de obras como el Don Juan Tenorio de Zorrilla, La pata de Cabra de Grimaldi o el Don Álvaro o la fuerza del sino del Duque de Rivas, eran situaciones sólo posibles gracias a la caja italiana, cuya estructura de telones y bambalinas, posibilitaba, entre otras cosas, la fastuo- 
sidad y diversidad de los decorados, sus rápidos cambios o el desarrollo de la teatralidad, uno de los elementos más acusados especialmente en el Romanticismo, y que es posible gracias a los avances escenotécnicos y mecánicos del teatro.

Efectivamente, uno de los elementos que más y mejor define la literatura dramática del siglo XIX, del drama romántico a la ópera, es la teatralidad. Una concepción de la escena basada en el espectáculo de la vista y en el desarrollo práctico del concepto mismo del teatro, consciente hasta límites insospechados de la voluntad de «mentira» que debe presidir toda representación, en paradójico contraste con el efecto de realidad que, desde la verosimilitud, también debe estar muy marcado en la representación. Así, pues, el teatro en el siglo XIX es un juego de tensiones opuestas entre la pura ficción, con sus leyes propias en torno a la libertad del proceso creador de la obra dramática, y el marco moral y realista donde se debe desarrollar esa misma ficción. Un problema que retrataría muy acertadamente Tamayo y Baus en Un drama nuevo donde realidad, ficción y teatro dentro del teatro componen un interesante mosaico de posibilidades argumentales y efectos escénicos.

Con todo, la teatralidad, primero del drama romántico y la comedia de gran espectáculo, y después del drama burgués y el género chico, crea unas nuevas normas de composición ético-estéticas en torno a la escena, cuyo fundamento principal consiste en la utilización, sin ningún tipo de reparos, de todos los mecanismos que desde la trampa de la tramoya pueden contribuir a contar una historia, dando, así, efecto de realidad a situaciones absolutamente ya no irreales sino completamente imposibles, aunque aceptadas dentro de los nuevas coordenadas y convencionalismos que conducen en desarrollo de la escena a lo largo del siglo XIX.

Sólo así podían entenderse, por ejemplo, determinadas escenas del Don Juan de Zorrilla, como son las denominadas «La sombra de doña Inés» (acto primero, parte segunda), «La estatua de don Gonzalo» (acto segundo, parte segunda) o el final «Misericordia de Dios y apoteosis de amor» (acto tercero, parte segunda), dentro de la tradición de la comedia de magia (Gies 1990). En todas ellas, el ambiente fantasmagórico y sepulcral se desarrolla plenamente a una escenografía muy cómplice con la trama, donde además se incluye una iluminación blanca propia de la luz de gas que se incorpora a los sistemas de alumbrado del teatro a principios del Romanticismo, y una maquinaria que posibilita, entre otras cosas, la aparición de ángeles, flores que se abren o efectos como el que se explica en la última acotación:

(Cae don Juan a los pies de doña Inés, y mueren ambos. De sus bocas salen sus almas representadas en dos brillantes llamas, que se pierden en el espacio al son de la música. Cae el telón.) 
En relación con los problemas de la iluminación, el siglo XIX asiste a otra transformación teatral importante al incorporar la luz de gas frente a otras formas más arcaicas para la representación. Así, en 1817 el Lyceum Theatre de Londres utiliza por primera vez el alumbrado de gas, dando a la representación una luz pálida muy acorde con la nueva estética romántica que entusiasmaria al público. A partir de 1860 se pudo apagar completamente la iluminación, dejando toda la sala a oscuras, y pudiéndose concentrar toda la luz en el escenario. De esta manera se hacía realidad el sueño de los escenógrafos italianos del siglo XVI, quienes en su diseño de la caja italiana habían contemplado este efecto, imposible entonces, pero que ahora contribuía, de manera incuestionable, al efecto de ilusión de realidad que pretendía el invento italiano.

A partir de este momento, todos los grandes teatros incorporan el nuevo invento, símbolo por otra parte del progreso y la modernidad burguesa. Así, en 1822 la Ópera de París utilizó el nuevo alumbrado, en 1833 el mítico Teatre la Fenice de Venecia, en 1837 la Chesnut Street Opera House de Filadelfia, y en 1847 el Teatro del Liceo de Barcelona (Salvat 1981; Simón Palmer 1989). En ciudades como Cádiz, por ejemplo, el gas de alumbrado se utiliza por primera vez en 1851 en el Teatro Principal y en 1862 en la escalera y el vestíbulo.

Esta innovación técnica consiguió explorar muchas de las opciones estéticas de la escena decimonónica. Contribuyó de manera más que considerable al desarrollo, por ejemplo, del drama romántico que se apoyaba en una escenografía de gran espectáculo y llena de fuertes matices de iluminación. De la misma manera, posibilitó la rápida implantación del realismo escénico en la segunda mitad del siglo (Rubio Jiménez 1988). Técnicamente fue posible iluminar las luces de las bambalinas, lo que se tradujo en la utilización de cielos rasos y plafones que ayudaban a crear aquella sensación de atmósfera que anteriormente resultaban muy artificiales. Como nos indica Salvat:

Esta nueva luz misteriosa y filosófica traía consigo grandes ventajas e innovaciones para el espectáculo teatral. La imagen era rechazada sin vibración por la retina del espectador y se conseguía una mayor sensación de profundidad en la caja cerrada del escenario. Es más, la luz de gas conseguia dar una dimensión pictórica al escenario, llegando a crear una atmósfera, un ambiente particular, un tono delicioso y suave que difícilmente se había conseguido en las iluminaciones anteriores. (1981, pág. 14).

La inclusión de esta nueva atmósfera entre los elementos de la representación va a repercutir de manera muy determinante en la configuración estética de los textos dramáticos. Ello, unido a los otros cambios -la nueva verosimilitud realista, la concepción moral del texto dramático, la implantación de la caja italiana y el juego bidimensional que conlleva- determinará el texto teatral como una valoración más de la realidad, siguiendo así los pasos de la novela realista y, más 
tarde, del naturalismo, hasta la publicación en 1881 del manifiesto del teatro naturalista: Le Naturalisme au Théâtre de Zola ${ }^{2}$. De Balzac a Ibsen se podrá rastrear, pues, uno de los cauces más esenciales del espectáculo burgués, desde la «pièce bien faite» hasta el gran drama de ideas ibseniano y sus continuaciones en la obra de August Strindberg, Bjoernstjerne Bjoernson, Luigi Pirandello, Bernald Shaw o Jean-Paul Sartre, entre otros. En el caso español conviene recordar, por ejemplo, la renovación del drama que supuso la incorporación a la literatura dramática de Galdós, el nuevo teatro social de Dicenta o el drama rural de Feliú y Codina, sin olvidar -claro está- el Teatro por Horas y el género chico ya en el último tercio del siglo XIX. Frente a esta línea «realista» de la escena también nos encontramos con un cierto vanguardismo encabezado por Alfred Jarry y su renovación de la mano del «nouveau théâtre», que desembocará en figuras tan emblemáticas del teatro moderno como Eugène Ionesco.

Pero si en todos los casos citados, la concepción teatral parte del nuevo marco técnico, también es cierto que el teatro más representado --las continuaciones historicistas, el neorromanticismo, la zarzuela y la ópera- también habían desarrollado una nueva concepción de la estética teatral, basada fundamentalmente, en la espectacularidad de la escena y la utilización, hasta el agotamiento, de todos los recursos de la nueva escenotecnia.

Como síntesis de todas estas posturas, un ejemplo muy convincente, y que simboliza la Era del Teatro Burgués además de los complejos derroteros del espectáculo teatral en la segunda mitad del siglo, lo encontramos en las líneas teóricas y prácticas que del teatro nos ofrece Richard Wagner -ahí quedan sus ensayos $E l$ arte y la revolución (1849), La obra de arte del porvenir (1850) y Ópera y drama (1851)-, con su gran revolución del espectáculo musical y su concepción del espectáculo teatral. La ópera wagneriana representaba con toda eficacia los avances de la cultura europea. Así, su modo de entender la escenografía, por ejemplo, llevaba hasta límites insospechados todos los elementos y mecanismos ensayados en el drama romántico, a los que se le otorgaba ahora una dimensión desmesurada y que implicará la culminación de todo el proceso evolutivo del teatro burgués, con el que, curiosamente, va a mantener una contradictoria, pero consciente, relación de simbolización y ejemplaridad de la modernidad y el progreso que representa la sociedad burguesa, frente a una actitud de rechazo estético de los usos y los comportamientos de ese mismo cuerpo social al que sirve de emblema y al que pertenece. Como dato curioso de todo ello, baste recordar la ruidosa protesta de la burguesía catalana cuando se intentó apagar la sala del Liceo durante las funcio-

${ }^{2}$ La publicación del texto de Zola supone el punto de partida de la revolución objetivista de la escena, que llevará a cabo en Francia André Antoine, y cuyo desarrollo nos conduce, por ejemplo, al realismo épico de Brecht o su marcada utilización por Peter Weiss. 
nes de ópera, pues «si las señoras no podían lucir sus vestidos y sus joyas, el Liceo carecía de todo sentido social» (Salvat 1981, pág. 51) y la defensa de Wagner de la exclusiva iluminación de la caja teatral, frente a las otras zonas del teatro.

Pero si la utilización coherente de todos estos recursos había posibilitado el desarrollo del espectáculo teatral a lo largo del siglo XIX, al amparo de una burguesía muy cómplice con dichas transformaciones, no había tampoco que olvidar que ello también había sido posible gracias al nuevo edificio teatral, cuyos espacios dedicados al público parecían también grandes tramoyas con unas escenografías -que lo eran- y que no desmerecían en nada a lo que acontecía dentro del palco escénico (Fernández Muñoz 1985). En otras palabras, si el teatro evolucionó de una manera tan particular en el siglo de la burguesía, lo fue, precisamente, por la necesidad -y también la capacidad- que esa misma burguesía tenía de representarse a sí misma. Y nada mejor para tal representación que un lugar dedicado exclusivamente, desde su fachada exterior hasta los más pequeños detalles ornamentales, al lucimiento de los actores y verdaderos protagonistas y artífices del siglo XIX: la burguesía.

El teatro se convertía, con ello, en uno de los grandes espacios de la sociabilidad decimonónica. Tal vez, por esta razón, la escena del palco en la ópera parece un pasaje obligado para todo novelista y pintor urbano del siglo XIX que pretenda «retratar»su sociedad. Así, Manet, Renoir, Proust, Galdós, Zola, Stendhal, Flaubert o Clarín, en algún que otro momento, han dirigido su atención a este mundo, dando lugar con sus respectivas evocaciones a la figuración pictórica o literaria -según los casos- de unos personajes que determinan su protagonismo social por el lugar que, jerárquicamente, ocupan dentro de la sala teatral.

La convergencia cómplice, pues, de esta larga serie de elementos -público, actores, texto literario, escenografía, espacio, decorados, arquitectura- en un momento concreto y previamente convocado -el momento de la representaciónva a determinar el espacio del espectáculo, como un lugar que hubiera servido a Calderón como sólido ejemplo de que «el mundo es un teatro». La Era de la Burguesía supo, con ello, buscar sus espacios para reinterpretarse a sí misma con toda la eficacia de las grandes compañías teatrales, pero también con todos los medios posibles a su alcance. Supo construirse unos complejos escenarios provistos de una extraordinaria teatralidad cuya eficacia de comunicación y transmisión de unos símbolos de poder surtió el efecto deseado (Peláez 1998). Si para otras épocas de la historia de la escena podía predicarse que el mundo era un teatro -como lo era también ahora-, sin ningún tipo de dudas y con toda contundencia, el teatro en el siglo XIX conformaba otro mundo dentro de aquél, al que servía de espejo y que siempre resultaría mucho más elocuente, atractivo y fascinante que el mundo real. 


\section{BIBLIOGRAFÍA}

ARIAS DE Cossio, Ana María, 1991. Dos siglos de escenografia en Madrid, Madrid, Modadori.

BANú, Banú, 1989. Le rouge et or, Paris, Flammarion.

ESCOBAR, José, 1988. «La mímesis costumbrista», Romance Quarterly 35, págs. 261-270.

- 1994. «Literatura de «lo que pasa entre nosotros». La modernidad del costumbrismo», Sin fronteras. Homenaje a Maria Josefa Canellada, Madrid, Editorial Complutense, págs. 193-206.

FERNÁNDEZ MUÑoz, Ángel Luis, 1985. «Espacios de la vida social: los otros espacios de la arquitectura teatral», Arquitectura teatral en España, Madrid, MOPU, págs. 64-77.

GIES, David T., 1990. «Don Juan Tenorio y la tradición de la comedia de magia», Hispanic Review 58, págs. 1-17.

GraellS, Antoni Ramon, 1985. «El lugar del espectáculo», Arquitectura teatral en España, Madrid, MOPU, págs. 40-51.

JOVElLANos, Gaspar Melchor de, 1963. Memoria para el arreglo de la policía de los espectáculos públicos y sobre su origen en España. 1790. Obras de Don Gaspar Melchor de Jovellanos, T. XLVI, Madrid, BAE.

PELÁEZ, Andrés, 1998. «El teatro del siglo XIX, modelo para la pintura costumbrista». Costumbrismo Andaluz, J. Álavarez Barrientos y A. Romero FERRER (eds.), Sevilla, Universidad, págs. 107-124.

Pignarre, Robert, 1971. Histoire du théâtre, 9 éd, Paris, Presses Universitaires de France.

1975. Histoire de la mise en scène, Paris, Presses Universitaires de France.

Rodríguez Rubí, Tomás, 1860. Discurso acerca de la excelencia, importanciay estado presente del teatro (1847), Discurso de Ingreso de la Real Academia Española, Madrid, Imprenta Nacional, págs. 430-431.

ROMERo Ferrer, Alberto, 1996. «Problemas metodológicos para el estudio de la Historia del Teatro Español: contextualización y recepción del texto dramático», Pedagogía teatral: conceptos y métodos, Cádiz: FIT, Universidad, págs. 389-397.

Rubio JimÉnez, Jesús, 1988. «El realismo escénico a la luz de los tratados de declamación de la época», Realismo y Naturalismo en España en la segunda mitad del siglo XIX., Yvan Lissorgues (ed.), Barcelona, Anthropos, págs. 257-286.

- 1998. El conde de Aranda y el teatro, Zaragoza, Ibercaja.

SAlvat, Ricard, 1981. La illuminatió de gas i l'espectacle del XIX a Catalunya, Barcelona, Catalana de Gas y Electricidad. 
Seco Serrano, Carlos, 1973. Sociedad, literatura y política en la España del siglo XIX, Madrid, Guadiana.

Simón PAlmer, María del Carmen, 1989. El gas y los madrileños, Madrid, Gas Madrid y Espasa Calpe.

TAMBURINI, Luciano, 1983. L'Architettura dalle origini al 1936. Storia del Teatro Regio di Torino IV, Torino, Cassa di Risparmio. 